\title{
Effects of overweight on lung function
}

\author{
$\mathrm{K}$ P Fung, S P Lau, O K W Chow, J Lee, T W Wong
}

\begin{abstract}
Spirometric data from 1586 healthy children, who did not smoke, were analysed to examine the effects of overweight as measured by the body mass index (weight/height ${ }^{2}$ ) on lung function. Overweight ( 72 boys, 88 girls) was defined as on or above the 90th percentile weight for height. After having controlled for the confounding variables of height and age, there were positive partial correlations between body mass index and lung function in girls whose weight was normal, in overweight girls, and in boys whose weight was normal, but not in overweight boys. In contrast to adults, body mass index has a positive effect on lung function in girls, whatever their weight. No such correlation between body mass index and lung function was seen in overweight boys. The observations may be accounted for by distinct sex dependent patterns of fat distribution in children.
\end{abstract}

The effects of morbid obesity on respiratory function has been studied thoroughly in adults. Fat subjects tend to have lower lung volumes and less chest wall compliance. ${ }^{2}$ Information on lung function in children with normal lungs who are obese, but not morbidly so, is, however, sparse. The distribution of fat in adolescents differs from that in adults, and is sex dependent. ${ }^{3}$ Obesity, therefore, by its effect on the chest and diaphragm, may alter the lung function of children and adolescents differently from adults. Quetelet's index (weight/height ${ }^{2}$ ) is a body mass index for assessing obesity or overweight. ${ }^{4}$ We used it to evaluate the association between overweight and standing height and lung function in normal as well as nonmorbidly obese children.

\section{Patients and methods}

We studied 1586 normal Chinese schoolchildren who did not smoke (705 boys, 881 girls; age range $6 \cdot 5-20$ years) representing different social classes in Hong Kong. Weight $(\mathrm{kg})$ and standing height $(\mathrm{cm})$ were measured with a calibrated weighing scale and stadiometer by standard anthropometric methods. ${ }^{5}$ The ages of the subjects were calculated from the date of birth and the date of examination. Those with recent or chronic respiratory diseases, chest or skeletal deformities, morbid obesity, and congenital defects were excluded from the study. Spirometric data (forced expiratory volume in one second, forced vital capacity, vital capacity, peak expiratory flow rate, and forced midexpir- atory flow rate) were measured with a calibrated Vitalograph Spirotrac IIS machine in a standing position. Lung volumes were expressed in litres (body temperature, pressure, and saturation). The best of three reproducible readings was recorded for analysis. Both weight and height were considered simultaneously in interpreting the body build of children. In this study an overweight subject was arbitrarily defined as one whose weight was on or above the 90th percentile of the weight for height standard for the respective height groups from $110 \mathrm{~cm}$ onwards in steps of $10 \mathrm{~cm}$.

\section{STATISTICAL METHOD ${ }^{6}$}

The measurements of lung function have an exponential relationship with age, height, weight, and body mass index, so they were all transformed logarithmically (base $=10$ ) in statistical analyses. In bivariate linear regression analysis, lung function tests were the dependent variables and height and body mass index were the independent variables. The measurement 'age' was not included in the multiple regression analysis because of its high collinearity with stature $(r>0 \cdot 9)$. The comparative importance of a particular independent variable as a predictor of the dependent variable was estimated by the unit free standardised regression coefficients (mean and variance of the independent variable $=0$ and 1 , respectively). The exclusive effect of body mass index and stature on lung function was investigated by partial regression analysis that was adjusted for age and height for the former, or age and body mass index for the latter, after logarithmic transformation. Student's $t$ test was used to compare the means for the variables between the overweight and normal weight children, and to test the significance of the differences between regression coefficients in simple and partial regression analyses.

\section{Results}

Seventy two boys and 88 girls were classified as overweight according to our criteria while the remaining children (633 boys and 793 girls) from the same population were considered as not overweight; the median weights are shown in table 1 . The means (SD) for the body mass index $(\times 1000)$ of the overweight groupsboys $=2 \cdot 32(0.37)$ and girls $2 \cdot 25(0.38)$-were greater than those of the corresponding normal weight groups-boys 1.71 (0.37) and girls 1.68 $(0 \cdot 23)(\mathrm{p}<0 \cdot 05)$. There was no difference in

body mass index, however, between the over-
Correspondence to: Dr Lee.

Accepted 13 November 1989 
Table 1 Median weights $(\mathrm{kg})$ for normal and overweight boys and girls

\begin{tabular}{lllll}
\hline & Boys & & Girls \\
Height $(\mathrm{cm})$ & Normal weight & Overweight & Normal weight & Overweight \\
\hline$<120$ & $20 \cdot 2(\mathrm{n}=52)$ & $24 \cdot 5(\mathrm{n}=6)$ & $19 \cdot 4(\mathrm{n}=57)$ & $24 \cdot 5(\mathrm{n}=6)$ \\
$120-9$ & $23 \cdot 2(\mathrm{n}=109)$ & $29 \cdot 2(\mathrm{n}=12)$ & $23 \cdot 0(\mathrm{n}=143)$ & $28 \cdot 7(\mathrm{n}=16)$ \\
$130-9$ & $29 \cdot 0(\mathrm{n}=107)$ & $50 \cdot 1(\mathrm{n}=12)$ & $28 \cdot 0(\mathrm{n}=111)$ & $36 \cdot 9(\mathrm{n}=12)$ \\
$140-9$ & $34 \cdot 8(\mathrm{n}=94)$ & $56 \cdot 6(\mathrm{n}=10)$ & $34 \cdot 8(\mathrm{n}=128)$ & $48 \cdot 2(\mathrm{n}=14)$ \\
$150-9$ & $50 \cdot 6(\mathrm{n}=73)$ & $70 \cdot 8(\mathrm{n}=15)$ & $43 \cdot 8(\mathrm{n}=257)$ & $62 \cdot 6(\mathrm{n}=28)$ \\
$160-9$ & $57 \cdot 6(\mathrm{n}=72)$ & $73 \cdot 2(\mathrm{n}=9)$ & $52 \cdot 0(\mathrm{n}=90)$ & $67 \cdot 3(\mathrm{n}=2)$ \\
$\geqslant 170$ & $34 \cdot 8(\mathrm{n}=633)$ & $53 \cdot 4(\mathrm{n}=72)$ & $35 \cdot 8(\mathrm{n}=793)$ & $49 \cdot 4(\mathrm{n}=88)$ \\
\hline Total & & & &
\end{tabular}

weight boys and girls $(p=0 \cdot 279)$. The Pearson correlation coefficients between log body mass index and log height in all groups were less than 0.56 , and therefore justified the inclusion of these two moderately correlated variables in the same regression model.

As assessed by the standardised and partial regression coefficients, standing height was more important than body mass index in predicting lung function (table 2). The contribution of body mass index to the prediction of lung function was variable, and seemed to be different between the boys and girls as well as between the normal and overweight subjects. Body mass index significantly contributed to the prediction of all the tests in girls and all but forced midexpiratory flow rate in boys $(p<0.05)$. The standardised regression coeffi- cients of log body mass index for the normal and overweight girls and normal boys had a range of 0.05 to $0.42(p<0.05)$ for all tests but forced midexpiratory flow rate. Body mass index made no significant contribution to lung function in the overweight boys $(p>0 \cdot 27)$. The effect of overweight on lung function was apparently sex dependent. The unit free standardised regression coefficients of body mass index for overweight girls were comparatively greater than those for normal girls for the corresponding coefficients of stature. This did not, however, seem to be the case for boys, in whom the standardised regression coefficients of body mass index for the overweight boys $(0.012$ to 0.094$)$ did not differ significantly from zero. This sex dependent pattern of the effect of body mass index could be further elaborated by partial

Table 2 Simple and standardised regression coefficients of height and body mass index on each measurement of lung function

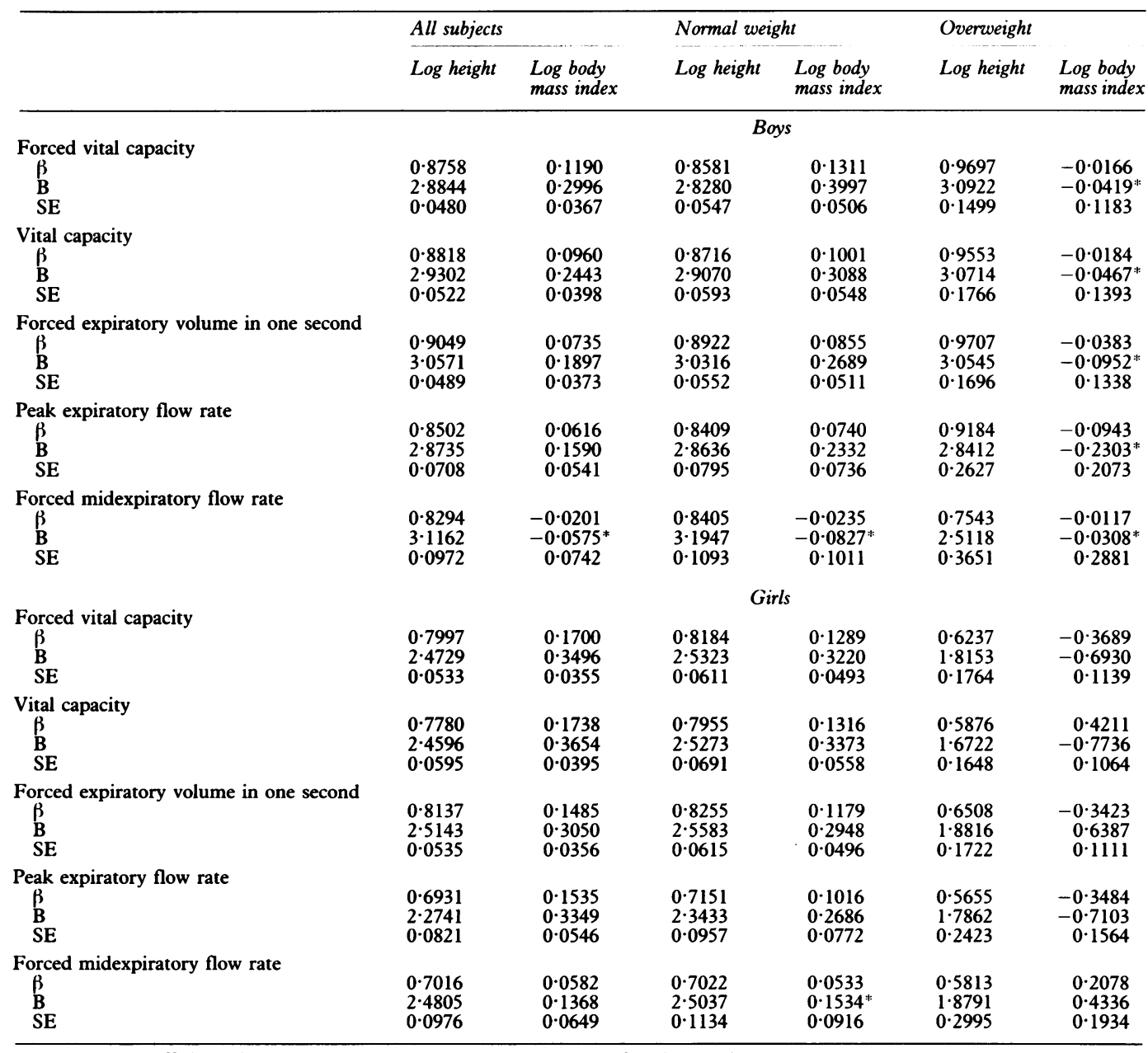

$B=$ regression coefficient, $\beta=$ standardised $B$, and $S E=$ standard error of $B .{ }^{*} p<0.05$. 
Table 3 Partial regression coefficients of height and body mass index on each measurement of lung function

\begin{tabular}{|c|c|c|c|c|c|c|}
\hline & \multicolumn{2}{|l|}{ All subjects } & \multicolumn{2}{|c|}{ Normal weight } & \multicolumn{2}{|l|}{ Overweight } \\
\hline & Log height & $\begin{array}{l}\text { Log body } \\
\text { mass index }\end{array}$ & Log height & $\begin{array}{l}\text { Log body } \\
\text { mass index }\end{array}$ & Log height & $\begin{array}{l}\text { Log body } \\
\text { mass index }\end{array}$ \\
\hline & \multicolumn{6}{|c|}{ Boys } \\
\hline Forced vital capacity & 0.6108 & $0 \cdot 3040$ & 0.5869 & 0.3048 & $0 \cdot 7616$ & -0.0407 \\
\hline $\mathrm{t}$ & $20 \cdot 426^{*}$ & $8 \cdot 632^{*}$ & $18 \cdot 179^{*}$ & $8.026^{*}$ & $9.691^{*}$ & $-0 \cdot 336^{* *}$ \\
\hline Vital capacity & 0.5873 & $0 \cdot 2380$ & 0.5617 & $0 \cdot 2215$ & $0 \cdot 7229$ & -0.0388 \\
\hline $\mathrm{t}$ & $19 \cdot 212^{*}$ & $6 \cdot 487^{*}$ & $17 \cdot 026^{*}$ & $5.697^{*}$ & $8 \cdot 627^{*}$ & $-0 \cdot 321^{* *}$ \\
\hline Forced expiratory volume in one second & 0.6262 & $0 \cdot 2030$ & 0.6097 & $0 \cdot 2083$ & $0 \cdot 7074$ & -0.0854 \\
\hline & $21 \cdot 267^{*}$ & $5 \cdot 488^{*}$ & $19 \cdot 292^{*}$ & $5 \cdot 341^{*}$ & $18 \cdot 009^{*}$ & $-0 \cdot 707^{* *}$ \\
\hline Peak expiratory flow rate & 0.3915 & $0 \cdot 1237$ & 0.3888 & $0 \cdot 1256$ & 0.3890 & $-0 \cdot 1392$ \\
\hline 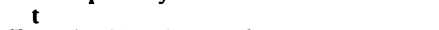 & $11 \cdot 264^{*}$ & $3 \cdot 302^{*}$ & $10 \cdot 582^{*}$ & $3 \cdot 175^{*}$ & $3 \cdot 481^{*}$ & $-1 \cdot 160^{* *}$ \\
\hline \multirow[t]{2}{*}{$\begin{array}{l}\text { Forced midexpiratory flow rate } \\
t\end{array}$} & $\begin{array}{l}0 \cdot 3161 \\
8 \cdot 820^{*}\end{array}$ & $\begin{array}{l}-0.2260 \\
-0.598^{* *}\end{array}$ & $\begin{array}{l}0 \cdot 3146 \\
8 \cdot 313^{*}\end{array}$ & $\begin{array}{r}-0.0367 \\
0.921^{*}\end{array}$ & $\begin{array}{l}0 \cdot 2667 \\
2 \cdot 282^{*}\end{array}$ & $\begin{array}{l}-0.0103 \\
-0.085^{*}\end{array}$ \\
\hline & & & \multicolumn{2}{|c|}{ Girls } & & \\
\hline Forced vital capacity & $\begin{array}{r}0 \cdot 5983 \\
22 \cdot 112^{*}\end{array}$ & $\begin{array}{l}0 \cdot 2872 \\
8 \cdot 878^{*}\end{array}$ & $\begin{array}{r}0.5998 \\
21.056^{*}\end{array}$ & $0 \cdot 2131$ & $\begin{array}{l}0.5687 \\
6.336^{*}\end{array}$ & $\begin{array}{l}0 \cdot 4233 \\
4 \cdot 283^{*}\end{array}$ \\
\hline Vital capacity & 0.5681 & $0 \cdot 2773$ & 0.3248 & $\begin{array}{l}6.125 " \\
0.0977\end{array}$ & 0.5340 & 0.4857 \\
\hline $\mathbf{t}$ & $20 \cdot 445^{*}$ & $8 \cdot 547^{*}$ & $19 \cdot 794^{*}$ & $5.952^{*}$ & $5 \cdot 789^{*}$ & $5 \cdot 092^{*}$ \\
\hline Forced expiratory volume in one second & 0.5856 & 0.2405 & 0.5809 & $0 \cdot 1857$ & 0.5876 & 0.3850 \\
\hline $\mathrm{t}$ & $21 \cdot 395^{*}$ & $7 \cdot 339^{*}$ & $20 \cdot 045^{*}$ & $5 \cdot 309^{*}$ & $6.656^{*}$ & $3 \cdot 824^{*}$ \\
\hline Peak expiratory flow rate & 0.2794 & $0 \cdot 1441$ & $0 \cdot 2725$ & 0.0806 & $0 \cdot 2644$ & 0.3871 \\
\hline ( & $8 \cdot 617^{*}$ & $4 \cdot 312^{*}$ & $7 \cdot 955^{*}$ & $2 \cdot 272^{*}$ & $3 \cdot 544^{*}$ & $3 \cdot 848^{*}$ \\
\hline Forced midexpiratory flow rate & 0.2821 & 0.0226 & 0.2663 & 0.0254 & 0.3336 & 0.0896 \\
\hline $\mathbf{t}$ & $8 \cdot 707^{*}$ & $0.669^{* *}$ & $7 \cdot 761^{*}$ & $0 \cdot 715^{* *}$ & $3 \cdot 243^{*}$ & $0.825^{*}$ \\
\hline
\end{tabular}

${ }^{*} \mathrm{p}<0 \cdot 05 ;{ }^{* *} \mathrm{p}>0 \cdot 05 ; t$ value (Student's $t$ test).

regression analysis of the overweight, normal, and combined groups after adjusting for the confounding variables of age and height (table 3). Body mass index correlated positively with all tests except midexpiratory flow rate for normal boys as well as normal and overweight girls $(p<0.05)$, but no such correlation was found for overweight boys.

\section{Discussion}

Schwartz et al recently reported a positive correlation between Quetelet's index and all the tests that we used in a large group of young people. ${ }^{7}$ Our study showed a similar association between body mass index and the various measurements of lung function, not only in normal boys and girls, but also in the group of overweight girls. These findings are consistent with the well established observation of a negative correlation between lung function and body mass index in adults; that is, fat adults have smaller lung volumes. ${ }^{1}$ In normal adolescents boys, and particularly in normal girls, fat tends to be deposited at the extremities rather than on the trunk $^{3}$; lung function is thus not adversely affected, and there was no negative correlation between body mass index and lung function in normal subjects. Body mass index is not a reflection merely of fat tissue-it cannot differentiate between muscles, bone, and fat. ${ }^{4}$ In normal subjects, a positive correlation between body mass index and lung function may be a reflection of the strength of respiratory muscles, and the amount of effort put into doing the spirometric tests.

In overweight or obese subjects, however, body mass index may roughly reflect true adiposity. ${ }^{4}$ Partial regression analysis assessed the independent effect of overweight expressed as body mass index on the measurements of lung function by holding height and age constant. The positive partial correlation between body mass index and lung function that was seen in overweight girls was strikingly absent in over- weight boys. This sex discrepancy may be explained by the distinct fat patterns in boys and girls. Obese boys deposit fat in the abdomen while obese girls deposit fat in the subscapular area. ${ }^{3}$ By decreasing the expiratory reserve volume, the abdominal fat reduces the forced vital capacity and forced expiratory volume in one second in overweight boys. ${ }^{1}$ The decrease in forced midexpiratory flow rate was probably the result of a decrease in vital capacity as well as an increase in airway closure and air trapping in the dependent parts of the lung. ${ }^{8}$

Height is a far more important predictor of lung function than body mass index, as shown by a much larger standardised regression coefficient. Our data have, however, shown a small but interesting bias as a result of overweight. This minor bias does not usually preclude the use of the usual predictors or justify including body mass index in routine lung function estimation, and nor should abnormal lung function be considered to be the result of obesity or overweight rather than of intrinsic lung disease. Nevertheless, adjustment for confounding bias caused of obesity may be essential for accurate comparisons of lung function in clinical studies of fat children.

We divided our children into overweight and normal groups according to an arbitrary criterion (on or above the 90th percentile of the weight for height standard), though both weight and height are continuous variables. This study shows semiquantitatively how overweight affects lung function in children. The choice of another definition of overweight or obesity may result in a description quantitatively different from-but likely to be qualitatively similar to-that reported in this study.

In summary, body mass index seems to affect lung function in children quite differently from adults. There is a positive correlation between lung function and body mass index in normal boys and girls. A similar association was found in overweight girls but not in overweight boys. This may be accounted for by different patterns of fat distribution in boys and girls. 
We thank Dr NS Tsoi, Dr SC Chan, Dr KW Lun, and the late

Dr SY Chu fro help in data collection, and the school head-

masters of the participating schools for their support of the study.

1 Ray CS, Sue DY, Bray G, Hansen JE, Wasserman K. Effects of obesity on respiratory function. Am Rev Respir Dis 1983; of obesity on respiratory function. Am Rev Respir Dis 1983;

2 Bae K, Ting EY, Giuffrida JG. The effect of changes in the body position of obese patients on pulmonary volume and ventilatory function. Bull NY Acad Med 1976;52:830-7. 3 Hattor K, Becque MD, Katch VL, et al. Fat patterning of adolescents. Ann Hum Biol 1987;4:23-8.

4 Roche AF, Siervogel RM, Chumlea WC, Webb P. Grading body fatness from limited anthropometric data. Am $\mathcal{F}$ Clin Nutr 1981;34:2831-8.

5 Tanner JM. Physical growth and development. In: Forfar JO, Arneil GC, eds. Textbook of paediatrics. Edinburgh: Churchill Livingstone, 1984:304-5.

6 Draper NR, Smith H. Applied regression analysis. New York:

7 Schwartz JD, Katz SA, Fegley RW, Tockman MS. Analysis of spirometric data from a national sample of healthy 6- to 24-year-olds (NHANES II). Am Rev Respir Dis 1988; 138:1405-14

8 Naimark A, Cherniack RM. Compliance of the respiratory system and its components in health and obesity. $\mathcal{F}$ Appl Physiol 1960;15:377-82. 